\title{
Limitacions i reptes de la implicació ciutadana en la planificació de la ciutat. El cas de Va Cabanyal! ${ }^{1}$
}

\author{
Andrea Ariza Hernández \\ Màster en Antropologia Urbana, Migracions i Intervenció Social, \\ Universitat Rovira i Virgili \\ a.ariza.arq@gmail.com \\ Eva Raga Domingo \\ Escuela Técnica Superior de Arquitectura, \\ Universitat Politècnica de València \\ Francisco Azorin Chico \\ Escuela Técnica Superior de Arquitectura, \\ Universitat Politècnica de València \\ Isabel González Galindo \\ Escuela Técnica Superior de Arquitectura, \\ Universitat Politècnica de València
}

Resum: Amb aquest article es pretén generar un espai de reflexió sobre les limitacions i els reptes presents en la implicació de la ciutadania en els processos de planificació i transformació urbana a través de l'estudi de cas del barri del Cabanyal ${ }^{2}$ a València. Després de divuit anys amenaçat per la prolongació de l’avinguda Blasco Ibáñez, el nou govern local ${ }^{3}$ va promoure un procés par-

1 Va Cabanyal! va ser la proposta guanyadora d'un concurs convocat el 30/07/2015 per la Fundació InnDEA de l'Ajuntament de València — promotora de les estratègies d'innovació a la ciutat—, amb l'objectiu de seleccionar l'equip encarregat de redactar una Estratègia de Desenvolupament Urbà Sostenible i Integrat (EDUSI) que concorrera a una convocatòria de fons europeus. L'equip format per Carmel Gradolí, Francisco Azorín, Eva Raga, Isabel González, Barbara Branchini, Maite Ferrando, Inma Giner, Bruno Sauer i Sandra Vilaplana va presentar una proposta basada en ferramentes de recerca i acció participativa que es va desenvolupar entre els mesos de setembre de 2015 i gener de 2016.

2 Al llarg del present article utilitzarem la denominació Cabanyal per referir-nos al barri 2 del districte 11 de la ciutat de València, la denominació oficial del qual és Cabanyal-Canyamelar. Aquesta designació també inclou l'anomenat popularment Cap de França, que comprèn la franja ubicada entre el carrer Pintor Ferrandis i l'avinguda dels Tarongers.

3 El 24 de maig de 2015 tenen lloc les eleccions municipals que donen entrada al govern del consistori a un tripartit progressista - Compromís, PSPV-PSOE i València en Comú-, després de 20 anys de govern del 
ticipatiu durant l'últim trimestre del 2015 per a la redacció d'una Estratègia de Desenvolupament Urbà Sostenible i Integrat (EDUSI) per al barri, amb l'objectiu d'obtenir fons europeus per a regenerar la zona. Un conflicte urbà tan estès en el temps i amb tanta complexitat de capes i discursos com el del Cabanyal permet analitzar la participació social des diun marc conflictualista que és difícil obviar. A través de la implicació en aquest procés d'investigació de l'acció participativa, s'ha aprofundit en la transformació del conflicte, en les potencialitats d'un enfocament holístic i dialèctic, així com en les limitacions imposades, entre altres, per un marc administratiu molt rígid.

Paraules clau: Participació; planificació urbana; conflicte; Cabanyal.

Abstract: The aim of this article is to create a space of reflection about limitations and challenges of citizen participation in processes of urban planning and transformation. For that purpose, we used the case of Cabanyal neighborhood (Valencia, Spain). During the last quarter of 2015, the municipality of Valencia promoted a participative process to create an Integrated Sustainable Urban Development Strategy. Its goal was to receive European funds for the neighborhood rehabilitation. Such a long-lasting and difficult urban conflict is perfect to analyze social involvement in a challenging context, since it bound a lot of social layers and discourses together. Through involvement in this participatory action research process, it was possible to know more about conflict transformation and the possibilities of a dialectical and holistic approach. It also helped analyze the imposed limitations, among other reasons, because of an extremely rigid administrative framework.

Keywords: Participation; urban planning; conflict; Cabanyal.

\section{El Cabanyal, una lluita de divuit anys}

\subsection{La marca València}

Des de les acaballes de la dècada dels noranta, en el context del boom immobiliari espanyol i en la línia de la majoria de ciutats de l'àmbit nacional, València també va apostar per un model d'expansió urbana massiva. Al voltant del seu desenvolupament urbà, d'acord amb les dinàmiques de la ciutat postmoderna 
i amb la competició global interurbana, es va generar un discurs molt cuidat per part de les autoritats, tant locals com autonòmiques, per posar València en el mapa global de les ciutats, com un reclam publicitari capaç de dinamitzar el turisme (Ruiz y García, 2013). Aquesta estratègia es va impulsar majoritàriament per dos tipus d'actuacions: els "megaprojectes" i la celebració d'esdeveniments internacionals, tal com matisa l'antropòloga valenciana Josepa Cucó:

La bombolla valenciana es va articular mitjançant la connexió de cinc elements: esdeveniments d'art contemporani, espais temàtics, trobades mundials mediàtiques, esdeveniments esportius globals i icones arquitectòniques, tots ells concentrats en un "àrea global" o "glolugar" delimitada per la Ciutat de les Arts i les Ciències i el remodelat Port de València (Cucó, 2013: 21).

Es tracta de projectes com la ZAL (Zona d'Activitats Logístiques), la Ciutat de les Arts i les Ciències, la Marina Real Juan Carlos I o el circuit de fórmula 1, així com esdeveniments com la visita del papa Benet XVI per a la V Trobada Mundial de la Família (2006) o la Copa Amèrica (2007).

Tot a punt per tal de captar el turista global, un ciutadà del món amb cert nivell econòmic que arriba a València dispost a assistir a esdeveniments de repercussió internacional o a consumir espais urbans atractius. És així que quasi totes les inversions urbanístiques del govern valencià en les darreres dues dècades han estat focalitzades en àrees perifèriques de la ciutat, en concret en el front litoral. "Dejar de darle la espalda al mar" i transformar la façana marítima va ser la punta de llança del consistori de Rita Barberà, ${ }^{4}$ i en aquest sentit el Cabanyal es va convertir a la fi del segle en un punt estratègicament central en el desenvolupament de la política urbana de la ciutat. Perllongar una avinguda que anara des de pràcticament el centre de la ciutat fins a la platja a través dels Poblats Marítims i que, com a conseqüència, destruïra la seua trama originària, era el remat final d'una sèrie de projectes que, segons l'ajuntament valencià, posaven en valor la relació de València amb la mar. No obstant això, l'oposició veïnal, organitzada des del primer moment en què es féu pública la iniciativa del consistori, ha convertit el barri del Cabanyal en un símbol de resistència per a la ciutat.

4 Rita Barberà fou alcaldessa de València en el període de govern del Partit Popular comprès entre l'any 1995 i 2015. 


\subsection{El Cabanyal i el PEPRI de 1997}

El barri del Cabanyal està situat a uns $3 \mathrm{~km}$ del nucli històric de València. El barri, l'origen del qual es remunta a principis del segle XvirI, va ser municipi independent sota el nom de Poble Nou de la Mar entre 1837 i 1897, moment en el qual la ciutat l'annexiona. És també en aquesta època, al segle xix, quan València comença a construir els seus eixamples i a enderrocar les seues muralles (més concretament el 1865).

A l'inici de 1883 comença a manifestar-se per primera vegada l'interès municipal per la creació d'una nova via de comunicació que aproxime el nucli urbà a les platges, lloc d'estiueig de la burgesia valenciana. En eixe sentit, no solament es busca un accés alternatiu al camí del Grau -actual avinguda del Port-, saturat pel trànsit de mercaderies, sinó un eix susceptible de convertir-se en l'espina dorsal d'un nou eixample. És des d'aquest moment quan la idea del "Passeig al Mar" -dibuixat sobre la traça de l'actual avinguda Blasco Ibáñez- ha condicionat, d'una o altra manera, el desenvolupament dels barris mariners de València.

Així mateix, no serà fins al 1966, sota el paraigua del "desenvolupisme" i la primacia del transport privat, quan es plantege la possibilitat de prolongar l’avinguda Blasco Ibáñez a través del barri del Cabanyal per connectar amb una autopista costanera. El desenvolupament d'aquesta idea es deixava aleshores en mans del planejament diferit, que mai va arribar a redactar-se, però que va suposar una amenaça constant des d'aquell moment.

Finalment, en 1997 (31 anys després) l'Ajuntament de València, malgrat la qualificació de Conjunt Històric Protegit i Bé d'Interès Cultural (BIC), encarregà la redacció d'un Pla de Protecció i de Reforma Interior (PEPRI) que fracturava el barri per la meitat al perllongar l'avinguda Blasco Ibáñez fins a la mar. Una intervenció que implicava la destrucció de "1.600 habitatges allotjats en unes 575 edificacions, la qual cosa suposa més del $30 \%$ del patrimoni edificat en el barri del Cabanyal (en els seus límits estrictes, és a dir, entre l'avinguda del Mediterrani i el carrer Pintor Ferrandis)" (Herrero, 2010). Finalment, s'imposaven les lògiques i els fluxos de la "ciutat central" sobre el barri, una dinàmica que també va afectar la resta de l'àrea metropolitana, així com altres barris perifèrics i fonamentalment l'horta, que al llarg d'aquests anys ha vist reduïda la seua superfície de forma alarmant. 
Fig. 1: Plànol del PEPRI del Cabanyal-Canyamelar (versió 2001), elaborat per V. Corell i J. Monfort.

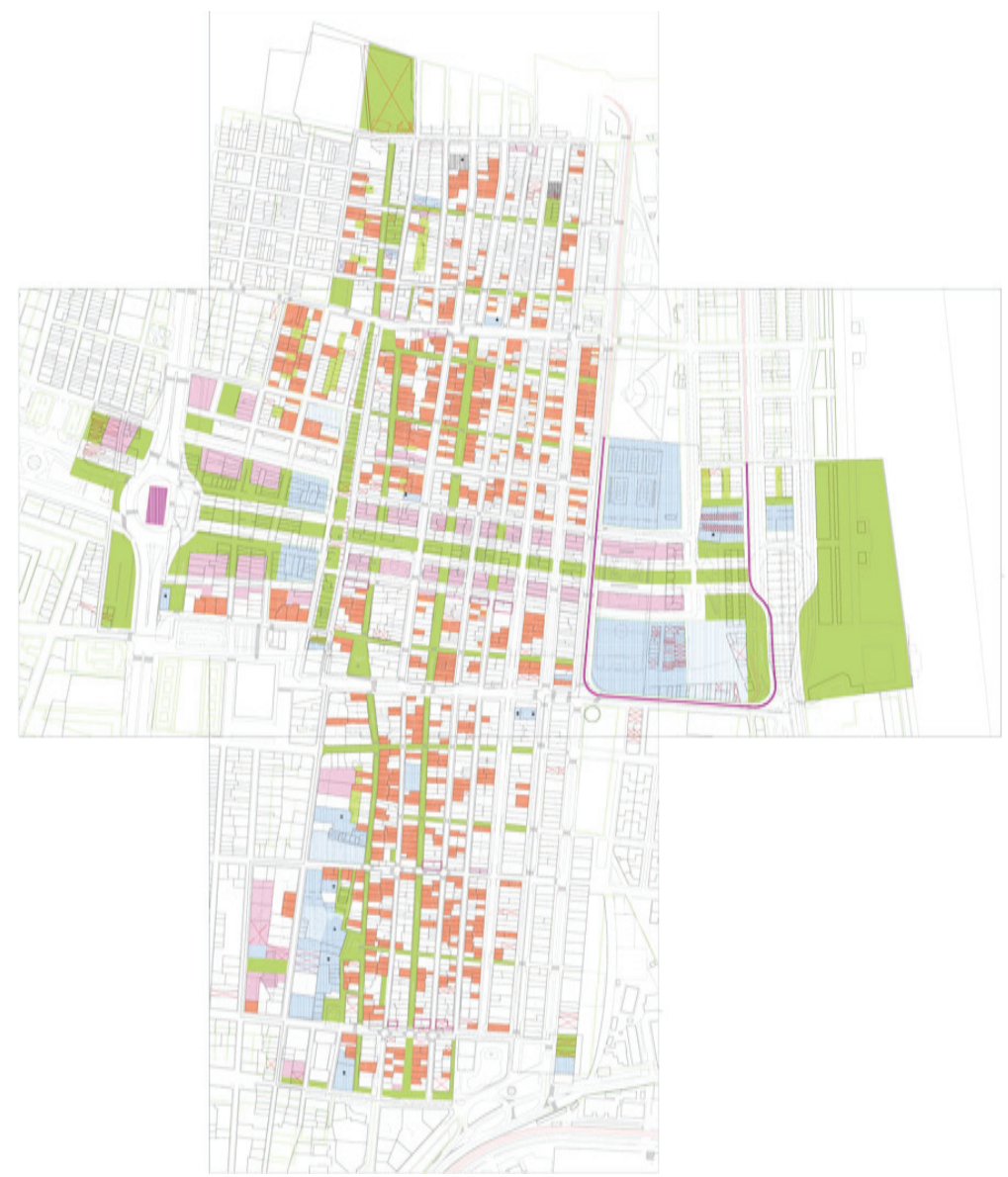

Mostra el projecte de prolongació de l’avinguda Blasco Ibáñez a través de la trama del barri del Cabanyal. Font: www.lapepri.com.

Amb l'aprovació del pla, començà un procés de degradació programada del barri que preveia, entre altres, l'enderrocament de múltiples habitatges i un setge constant a aquelles veïnes i veïns que no veneren facilment les seues cases $i$ no estigueren disposades a abandonar el barri. Així mateix, en la zona estrictament afectada per la prolongació començaren a ocupar-se algunes cases, fet 
que suposà l'augment de la població depenent al barri. Finalment, el pla mai va passar d'aquesta fase prèvia de degradació i abandonament gràcies a l'acció col-lectiva del veïnat.

\subsection{Mobilització ciutadana i lluita veïnal ${ }^{5}$}

En 1998 es crea la plataforma Salvem el Cabanyal, amb la finalitat de coordinar la postura a adoptar davant les tres alternatives presentades per l'Ajuntament en el procés d'exposició pública previ a l'aprovació del PEPRI. En un primer moment s'integren diferents associacions del barri, veïns i veïnes sense afiliació i els partits polítics de l'oposició. S'arrepleguen signatures per a respondre al procés de consulta ciutadana rebutjant les alternatives propostes, śorganitzen les primeres mobilitzacions públiques i sestén el debat a l'àmbit acadèmic. La plataforma interposa els recursos legals pertinents per tractar de paralitzar l'execució del planejament i comença a treballar en un projecte de rehabilitació. A més a més, visibilitza el conflicte a escala europea i denuncia el cas davant el Síndic de Greuges, ${ }^{6}$ ja que la degradació del barri va en augment i la deterioració dels edificis protegits cada vegada és més gran.

Malgrat açò, l'any 2000 l'Ajuntament rebutja una proposta promoguda i elaborada per la mateixa població del barri que proposa la rehabilitació sense prolongació. Llavors, la plataforma comença a impulsar una sèrie de mesures lligades a l'acció i molt vinculades a l'art i la cultura amb la intenció, tant de visibilitzar el conflicte com de treballar l'imaginari colllectiu i potenciar la cohesió del barri mitjançant l'ús de l'espai públic i la seua resignificació. Entre aquestes accions de difusió, que es van enriquir al llarg del conflicte amb la participació — sobretot en els últims anys- d'altres col+lectius, cal destacar l'experiència "Cabanyal Portes Obertes" i posteriorment "Cabanyal Íntim"7 Per la seua part, el consistori valencià continuava amb l'estratègia de legitimació del pla sostenint el continu deteriorament el barri i intensificant la pressió amb accions com

\footnotetext{
5 La font bibliogràfica principal d'aquest apartat és la cronologia del conflicte elaborada per la plataforma Salvem el Cabanyal. [En línia: http://www.cabanyal.com/nou/la-1luita/?llang=es, consultada el 23/05/2017].

6 El Síndic de Greuges de la Comunitat Valenciana és l'alt comissionat de les Corts Valencianes per a la defensa dels drets i llibertats compresos en el títol I de la Constitució i en l`Estatut d`Autonomia de la Comunitat Valenciana.

7 Cabanyal Portes Obertes i Cabanyal Íntim són projectes d'intervencions artístiques i arts escèniques que, desenvolupats fonamentalment a l'interior dels habitatges particulars del barri, tenen com a objectiu atraure la població de la resta de la ciutat perquè conega la realitat del Cabanyal i l'amenaça d'enderrocament.
} 
les dutes a terme l'any 2008, amb enderrocaments molt polèmics al tractar-se de construccions amb una alta càrrega simbòlica per al barri, com ara la Casa de la Palmera ${ }^{8}$

Després d'ajornaments, esperes, paralitzacions temporals i diversos recursos interposats, després de 12 anys de resistència i una elevadíssima repercussió en les vides quotidianes del veïnat, el 29 de desembre de 2009, gràcies a l'acció de la plataforma Salvem el Cabanyal, el Ministeri de Cultura publica una ordre ministerial que determina que el PEPRI del Cabanyal-Canyamelar suposa l'espoliació del conjunt històric i, en conseqüència, obliga l'Ajuntament de València suspendrén immediatament l'execució. Al juny de 2014 l'Ajuntament, persistent en els seus plans de futur per al barri, anuncia l'acord amb el govern central per a la modificació-adaptació del PEPRI del Cabanyal-Canyamelar. El nou pla mantindria la prolongació de l'avinguda Blasco Ibáñez, però modificaria les altures dels nous edificis, a la vegada que reduiria els enderrocaments un $35 \%{ }^{9}$ Davant aquesta proposta, els habitants del barri mantenen que, malgrat els canvis, segueix tractant-se d'un espoli al patrimoni valencià i, per tant, hi presenten al-legacions. El mateix mes en què finalitza la consulta pública, el Tribunal Suprem de Justícia de la Comunitat Valenciana (TSJCV) admet a tràmit el recurs interposat per Esquerra Unida contra el nou pla.

No obstant això, també existeix una part de la població a favor de la prolongació. Al gener de 2010 es forma una associació denominada "Sí Volem la Prolongació de Blasco Ibáñez", la qual dóna suport al pla proposat per l’Ajuntament del Partit Popular i justifica que és l'única manera possible de lluitar contra l'estigmatització i la degradació constant que continua patint el barri. Des de la seua creació, l'associació ha dut a terme campanyes de recollida de signatures i accions de visibilització amb pancartes a les balconades amb el lema "Sí Volem" (Santamarina, 2014). Aquesta situació fa molt visible el conflicte intern en el qual s'ha vist immers el mateix barri, on durant molt de temps s'ha fet creure a la població que solament existia la "disjuntiva de triar entre enderrocaments i marginació" (Cuesta, 2011:128). Tot i això, en 2012 va haver-hi un intent de traçar línies comunes entre diferents associacions del barri, entre les quals es trobaven Sí Volem i la plataforma Salvem el Cabanyal, però no va

8 Extret de notes de camp realitzades durant una visita al barri amb l'antropòloga Beatriz Santamarina a l'abril de 2015 en el marc d'altre treball d'investigació sobre Cabanyal.

9 Dades extretes de http://www.cabanyal.com/nou/resultat/?id=2402, consultat el 27/'01/2015. 
transcendir a la signatura d'un manifest sota el títol "Regenerar, revitalitzar, rehabilitar, recuperar el Cabanyal-Canyamelar. Junts podem, i ho volem ja”.

Finalment, davant un altre període d'espera pel recurs interposat, en les eleccions municipals de maig de 2015 es produeix un gir brusc en la vida del Cabanyal, molt esperat per certs sectors veïnals. El signe del govern local i autonòmic canvia, i deixa en minoria el grup del Partit Popular -l'únic partit que no havia signat en campanya electoral un manifest per a la protecció i rehabilitació del barri sense destrucció. En el primer ple ordinari del nou equip de govern, se sol-licita la suspensió del PEPRI a la Generalitat Valenciana i saproven unes normes urbanístiques transitòries que entraran en vigència fins que es redacte un nou pla. A banda, el 5 d'agost d'aquell any, la Regidoria de Participació, Drets i Innovació Democràtica de l'Ajuntament de València llança un concurs públic per a seleccionar l'equip tècnic que redactarà l'EDUSI per al període 2015-2020 al barri de Cabanyal-Canyamelar-Cap de França, amb la qual el consistori concorrerà a una convocatòria per a optar a un possible finançament provinent del Fons Europeu de Desenvolupament Regional (FEDER). Quasi un mes després de la publicació del concurs, es fa pública la resolució per mitjà de la qual se selecciona com a guanyadora la proposta presentada sota el lema "Va Cabanyal!".

\section{Va Cabanyal!}

\subsection{Enfocament metodològic del procés}

El plec del concurs posa l'accent en la perspectiva integral de la proposta, en la qual s'hauran d'abordar aspectes socials, urbanístics, mediambientals i de dinamització econòmica i cultural, així com en la implicació dels veïns i veïnes del barri, que ha de ser primordial a l'hora de definir les necessitats del lloc.

Sense oblidar el marc de l'ajuda europea i la filosofia en la qual es fonamenten els objectius d'Europa 2020, l'equip Va Cabanyal! (integrat per professionals del camp de la psicologia, la sociologia, l'arquitectura i la participació ciutadana, així com experts en finançament europeu) aposta per la recerca-acció participativa per a construir col-lectivament l'estratègia amb els actors i actrius implicats. Des d'una concepció holística de la realitat urbana, i en paraules textuals de l'equip, la prioritat central en la qual es basa aquest treball és "la 
recuperació i posada en valor, des d'un punt de vista social, cultural, ambiental i econòmic, de la identitat i la diversitat del barri, com a element integrador de les actuacions i de l'apoderament de la ciutadania" (Equip Va Cabanyal!, 2015: 5). Es parteix de la convicció que "només a través d'una participació activa i vinculant de la ciutadania podem construir entorns urbans integradors i dur a terme actuacions sustentables amb les quals realment els veïns se senten identificats, fent possible l'apoderament de la ciutadania i la millora de la qualitat de vida dels residents" (Equip Va Cabanyal!, 2015:33). És per açò que el procés participatiu es planteja des de tres pilars bàsics:

- La presa de consciència sobre les problemàtiques urbanes, territorials, socioeconòmiques i mediambientals comunes.

- Ladquisició i el desenvolupament de competències.

- La participació en igualtat de condicions de tots els agents.

\subsection{Fases}

Durant tot el procés, es desenvolupa conjuntament el treball tècnic i el treball de camp en contacte directe amb els veïns i veïnes del Cabanyal. La informació que es va generant és compartida i revisada tant en els grups de treball com en els mitjans digitals, i servirà com a base de les dinàmiques dels tallers colllectius.

El procés sestructura en quatre fases:

Una primera fase, anomenada d'anàlisi i diagnòstic, que pretén arreplegar tota la informació existent fins al moment i actualitzar-la amb el treball de camp per a poder desenvolupar una anàlisi multidimensional (física, mediambiental, energètica, social, econòmica, demogràfica, territorial, competencial, de governança i participació). Aquesta anàlisi fou el punt de partida per a l'elaboració col-lectiva del diagnòstic a través d'una metodologia DAFO (debilitats, amenaces, fortaleses, oportunitats) en un primer taller de convocatòria general.

La segona fase se centra en la sistematització de totes les propostes arreplegades fins al moment i la seua estructuració en funció dels resultats del DAFO i dels objectius específics de la convocatòria. Aquesta sistematització es va posar en comú en el segon taller general, en el qual es van revisar, corregir, incorporar $\mathrm{i}$ consensuar les diverses propostes. 
La tercera fase té com a objectiu la definició d’operacions ${ }^{10}$ concretes a partir de les propostes consensuades en el segon taller. Aquestes operacions, agrupades en línies d'actuació, es presenten en un últim taller general per a la seua priorització ciutadana.

La quarta i última fase va consistir en la redacció de l'estratègia i la posterior presentació al barri al desembre de 2015.

\subsection{Grups de treball}

El procés de redacció de l'estratègia va ser cogestionat junt amb la població a través de diversos grups de treball, entre els quals diferenciem un grup exclusivament tècnic i dos de tècnics-ciutadans:

- Grup Tècnic de Coordinació i Gestió. Equip multidisciplinari integrat per dotze persones de l'àmbit de la sociologia, la participació, l'arquitectura, l'urbanisme, l'antropologia urbana, la psicologia, la politologia, l'enginyeria agrònoma i el finançament europeu. El rol d'aquest equip va ser coordinar el procés i els espais de participació, gestionar la informació i finalment redactar l'estratègia presentada. En concret, van ser els arquitectes tècnics en participació qui van articular de forma més activa el procés participatiu, establint el seu lloc de treball al barri.

- Grup Motor. Format pels veïns i veïnes del barri més implicats en el procés i pels dos tècnics de participació. Es materialitzà com un grup heterogeni, sense intenció de representació, que realitzava funcions de seguiment i avaluació del procés, així com de generació d'informació complementària. Es reunia els divendres a les sis de la vesprada, per a facilitar la participació de la ciutadania, i el nombre d'assistents variava entre quinze i vint-i-cinc persones. El lloc de trobada salternava entre els diferents espais del barri amb la finalitat d'aprofitar els propis espais quotidians de reunió. Tot i que es va aconseguir que aquest grup es conformara com un espai de participació molt actiu, és cert que ha tingut les seues limitacions pel que fa al potencial amb el qual es concep en els processos de participació basats en metodologies dialèctiques (Red

10 La convocatòria de l'EDUSI estableix diversos objectius temàtics concrets. Dintre d'ells, cada estratègia definirà les línies d'actuació desitjades, que a la vegada estaran integrades per les seues corresponents operacions -també anomenades unitats executores. 
CIMAS, 2010), ja que la seua formació va ser massa forçada a causa del ritme temporal exigit per la convocatòria europea. No va haver-hi un temps de consolidació real del grup i no va arribar a acollir una representació de veus prou rica i plural.

- Grup de Comunicació i Difusió. Compost per set habitants del barri encarregats de donar suport a les tasques de comunicació i difusió del procés mitjançant l'atenció al públic en un horari de visites establert en l'oficina de barri, on aquelles persones que volien informació del procés -sobretot a la primera fase- podien preguntar presencialment tot allò que desitjaren. Independentment, també śaprofitaren els múltiples canals de difusió de les diferents associacions del barri, a més de comptar amb un periodista que feia el seguiment de les entrevistes i tallers realitzats amb vídeos que posteriorment es publicaven a la web pròpia. ${ }^{11}$

\subsection{Espais de participació}

Entenem per espais de participació dins del procés de Va Cabanyal! els mitjans, eines i llocs "formals" d'obtenció d'informació, debat i construcció col-lectiva, així com els mitjans i llocs "informals" en els quals es produeix intercanvi d'informació amb els veïns i veïnes del Cabanyal.

Loficina de participació sestableix com a lloc de treball de part de l'equip tècnic de Va Cabanyal! i punt d'informació, trobada i recollida de propostes. Sempre que era possible, per a dur a terme les entrevistes o dinàmiques participatives, tal com hem apuntat en el grup motor, s'acudia als espais de trobada de les associacions. Cal remarcar que aquest espai se situa dins de les oficines de Pla Cabanyal-Canyamelar, antiga oficina de l'empresa pública-privada que es dedicava a l'expropiació, compra i enderrocament d'habitatges, i que avui gestiona el patrimoni públic d'habitatge i la seua rehabilitació. Un dels objectius d'aquesta coexistència era l'apropiació d'aquest espai per part del barri, fins ara símbol de la seua destrucció.

A un nivell directe es van dur a terme entrevistes individuals amb veïns i veïnes, així com amb diferents representants de col-lectius i institucions, polítics i representants tècnics de l'Administració. Es van fer dinàmiques participatives tant amb associacions concretes com amb collectius que agrupen iniciatives

$11<$ www.vacabanyal.org > 
ciutadanes diverses, així com amb l'equip de govern i diferents serveis municipals. El disseny d'aquestes metodologies es realitzava en funció dels objectius transmesos pels colllectius implicats, desenvolupant dinàmiques més analítiques i altres més propositives que treballaven temàtiques concretes, com és el cas de la gentrificació o d’àmbits territorials determinats (l'entorn del carrer Sant Pere o el bloc de Portuaris). A més a més, es va elaborar un qüestionari exploratori amb el grup motor, disponible digitalment a través de la web o, físicament, a l'oficina de barri i en diferents comerços i equipaments de la zona.

Coincidint amb cadascuna de les fases es van dur a terme tres tallers de convocatòria general, organitzats com a sessions de treball on posar en comú tota la documentació generada per l'equip tècnic i la informació reunida al treball de camp. De nou, la limitació temporal i l'enfocament del procés va acabar per convertir els tècnics en els agents encarregats d'estructurar i gestionar tota la informació rebuda, sistematitzar-la (segons l'esquema establert per la convocatòria de fons europeus) i retornar-la en aquests tallers generals. També es va obrir un espai específic de participació per als més joves, "Va Cabanyal! Infantil”, que va desenvolupar activitats en quatre dels col.legis de l'àrea.

Pel que fa a les vies digitals, es va apostar per la web com a principal canal d'informació, transparència i rendició de comptes (notícies, convocatòries, diari de camp" videoblog, balanç de comptes...). El correu electrònic ${ }^{12}$ s'utilitzà com a via preferent per a comunicacions, convocatòries i informació. El Twitter, juntament amb la cartelleria física, va esdevenir més un mitjà de convocatòria i seguiment que un canal dsinteracció o participació efectiu. Així, tots aquests espais de participació es constituïen alhora com a eines de difusió i comunicació del procés.

D'altra banda, les xarxes socials i els mitjans de comunicació del barri (fonamentalment Radio Malva) es van establir com a llocs informals o "no institucionalitzats" en els quals el debat i la reflexió al voltant del model de barri desitjat es produïa de manera continuada, donant veu sovint a posicions que havien decidit no implicar-se en el procés de redacció de l'EDUSI — com és el cas d'algunes associacions com l'Ateneu Llibertari ${ }^{13}$ o la Plataforma Sí Volem.

12 vacabanyal@gmail.com

13 Per aprofundir en les raons per les quals l'Ateneu Llibertari va decidir no involucrar-se en el procés: Grupo Aürt - Ateneu Llibertari del Cabanyal, 2015. De la Prolongació a la Gentrificació. Reflexions sobre el conflicte del Cabanyal. València. 


\section{Nous escenaris de conflicte}

\subsection{Nous plans per al "nou barri"}

En el moment en què sorgeix Va Cabanyal! i s'inicia el procés participatiu, després de divuit anys de degradació i conflicte continuat, la realitat socioeconòmica del conjunt Cabanyal és bastant particular. Donats els fets esdevinguts, es pot dir que el barri va ser sotmès a un vertader exercici de "mobbing immobiliari” (Santamarina, 2014:323). Es tractà d'induir la degradació, de consolidar una imatge de barri decadent, per exemple, al reduir la quantitat i la qualitat de la recollida de brossa. A més, l'Ajuntament va comprar múltiples habitatges, la majoria dels quals han estat deshabitats durant tot aquest període, altres ocupats o altres enderrocats, però en tot cas en un procés de deterioració continu. Davant aquest panorama, diversos propietaris decidiren emigrar i, com a conseqüència de tot plegat, el preu de l'habitatge va caure, fet que afavorí el procés d'expropiació dut a terme pel consistori per a executar la prolongació de l'avinguda. Alhora, durant el període existent entre l'aprovació i l'execució del pla, la situació descrita exerceix com a reclam per a cert tipus de població exclosa de les dinàmiques del mercat, que troba en el barri la possibilitat d'accedir a un lloc on assentar-se (Varea et alii, 2016), creant-se així borses de pobresa urbana.

Actualment, el pes de la població sense recursos econòmics i en situació d'exclusió social és elevat - i sovint invisibilitzat - i es concentra, la gran majoria de vegades, en la part central del barri, és a dir, la zona directament afectada pel pla derogat. D'altra banda, el Cabanyal és un dels barris de la ciutat amb més decreixement poblacional, així com amb una proporció de població notablement envellida (el percentatge de persones més grans de 65 anys és del $21,2 \%$ - superior a la mitjana de València, que es troba en un 18,99\%). La població dependent —un 36,6\% - també supera lleugerament el conjunt de la ciutat - 34,5\% - i pel que fa a la població estrangera registrada, el percentatge se situa al voltant del $15 \%$, quan la mitjana de la ciutat és un $12,5 \%{ }^{14}$

A més a més, part del veïnat assentat històricament al barri atribueix actualment certs problemes de convivència a la falta d'arrelament de la població nouvinguda -qüestió agreujada a causa de la segregació espacial, especialment de certs col-lectius vulnerables- $\mathrm{i}$ als comportaments "incívics" dels qui ocupen im-

14 Dades actualitzades a 1 de gener de 2015 per l'Oficina d'Estadística de l'Ajuntament de València. 
mobles (soroll, falta d'higiene...). Aquest últim aspecte, l'ocupació il.legal d'habitatges, s'identifica com un problema per qüestions de salut pública, vulneració de la propietat, etc. Lús de l'espai urbà per part de grups que resignifiquen certs indrets amb la seua presència sentén com una alteració de la convivència quotidiana, perquè provoquen l'”expulsió" dels ja assentats. Al mateix temps, continua havent-hi certa sensació d'inseguretat ciutadana associada al tràfic de drogues i a la delinqüència, ${ }^{15}$ la qual cosa contribueix al foment de la narrativa de degradació del barri i al cicle de vulnerabilitat social existent.

\section{Fig. 2: Cicle de vulnerabilitat social associada a la degradació del barri}

\section{Cabanyal.}

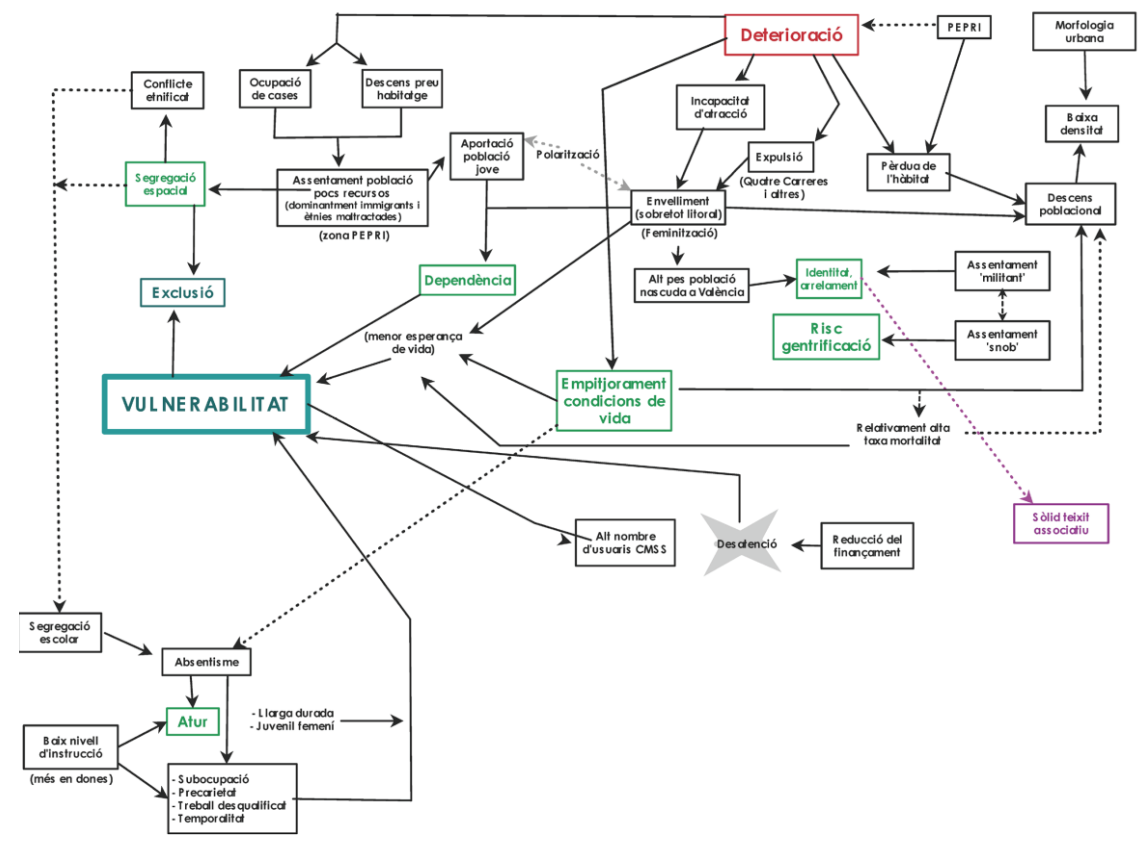

Elaborat durant el procés Va Cabanyal! en 2015

15 Extret de l'anàlisi social feta durant el procés Va Cabanyal! [En línia: <http://vacabanyal.org/wp-content/ uploads/2015/10/analisistecnicos/6.ANALISIS\%20SOCIAL_resum.pdf, consultat el 28/12/2016>]. 


\section{2 "El barri que volem"? Noves narratives d'un vell conflicte}

Amb les expectatives d'un nou pla i el procés de l'EDUSI damunt la taula, sobri el debat sobre el model urbà desitjat per al barri. El PEPRI del 98 i la lluita collectiva al voltant de la seua paralització havia deixat en stand by el desenvolupament urbanístic de l'entorn, fenomen que paradoxalment el va alliberar d'altres tipus de processos molt més subtils, però que han suposat la transformació del teixit socioeconòmic de la majoria de les façanes marítimes de les ciutats espanyoles. No obstant això, amb el canvi de govern -fins i tot cert temps abans- comencen a despertar-se diverses sensibilitats dins del que en un moment del conflicte es va considerar el conjunt d'acció ${ }^{16}$ en contra de la prolongació, així com a sentir-se veus que alerten d'una possible gentrificació del barri associada a la seua futura regeneració, la qual cosa podria suposar l'expulsió de les poblacions més vulnerables

En 2010, durant el I Congreso Internacional sobre Permanencia y Transformación en Conjuntos Históricos que va tindre lloc a València, la plataforma Salvem el Cabanyal i alguns sociòlegs van construir un sociograma ${ }^{17}$ per a reflexionar sobre l'acció collectiva entorn del conflicte existent (Herrero y Varea, 2012). Ja en eixe moment es va concloure que la plataforma tenia molta influència a l'hora de liderar la narrativa en contra de la prolongació i que, sobretot, estava centrant la seua estratègia mitjançant la mobilització d'actors amb molt poder —en alguns casos polític, en altres amb influència mediàtica. Amb tot, no s'hi havia aconseguit aglutinar certs actors socials del barri amb menys poder, que no estaven associats i que en aquell moment semblaven aliens al conflicte, com per exemple el collectiu romaní.

Davant les noves expectatives de canvi i amb el repte de fer front a la revitalització urbana de l'entorn, certs collectius del barri es desvinculen de la narrativa de la Plataforma i, a la vegada que s'engega Va Cabanyal!, posen en marxa un procés de participació autogestionat denominat Espai Veïnal. Aquest procés pretén "arreplegar necessitats i propostes amb les quals construir un model de

16 Entenem conjunt d'acció com "agrupació de diversos grups i sectors que tenen bona sintonia en un procés, normalment entorn d'una acció conjunta, i les estratègies de la qual poden fer-se compatibles" (CIMAS, 2010).

17 El sociograma és un instrument mitjançant el qual es grafien els actors i grups socials presents al territori $i$ les connexions i relacions existents (CIMAS, 2010). 
convivència per al barri"18 i posa l'accent en la necessitat d'evitar el risc que comporta la regeneració física del barri, ja que pot fomentar l'increment dels preus de l'habitatge i, com a conseqüència, la substitució de la població amb pocs recursos. Aquesta nova divisió al voltant dels grups en contra de la prolongació es fa visible durant el procés Va Cabanyal!, tant als espais de participació promoguts per l'equip tècnic com en les xarxes socials i els mitjans de comunicació, on śobri una batalla dialèctica que evidencia les dos noves posicions davant el repte de la regeneració del barri. D'una banda, la necessitat d'una intervenció urgent que centre les actuacions en la rehabilitació física, tant de l'espai públic com dels habitatges -sobretot en la zona més afectada pel pla derogat-, i pose fi a les situacions simptomàtiques de la degradació del barri (ocupació, tràfic de drogues...). I d'altra banda, un procés de regeneració urbana que compte amb tots els veïns i veïnes del barri i on sobretot els colllectius més vulnerables queden protegits davant el risc d'una possible elitització del Cabanyal.

Encara que no es grafien les relacions de poder, durant una reunió del grup motor es realitza amb els veïns implicats un mapa d'actors del barri on es pot observar com, en relació amb el sociograma realitzat en 2010 amb la plataforma, es redefineixen les relacions d'afinitat entre els actors veïnals i es reconfigura el conflicte al consolidar-se una nova fractura dins del teixit associatiu. Les diferències de percepció sobre "quin model de ciutat volem" es converteix en un enfrontament retòric on s'extrapolen dues posicions dominants que s'assumeixen com a part de l'autoidentitat dels grups socials, aspecte que aguditza la polarització del conflicte i dificulta el diàleg.

18 Extret de la pàgina de Facebook d'Espai Veïnal <https://www.facebook.com/pg/EspaiCabanyal/ about/?ref=page_internal, consultada el 30/12/2016>. 
Fig. 3: Comparació del sociograma realitzat en 2010 amb la plataforma Salvem el Cabanyal (Herrero y Varea, 2012) i el mapa d'actors elaborat amb el grup motor de Va Cabanyal! en 2015.

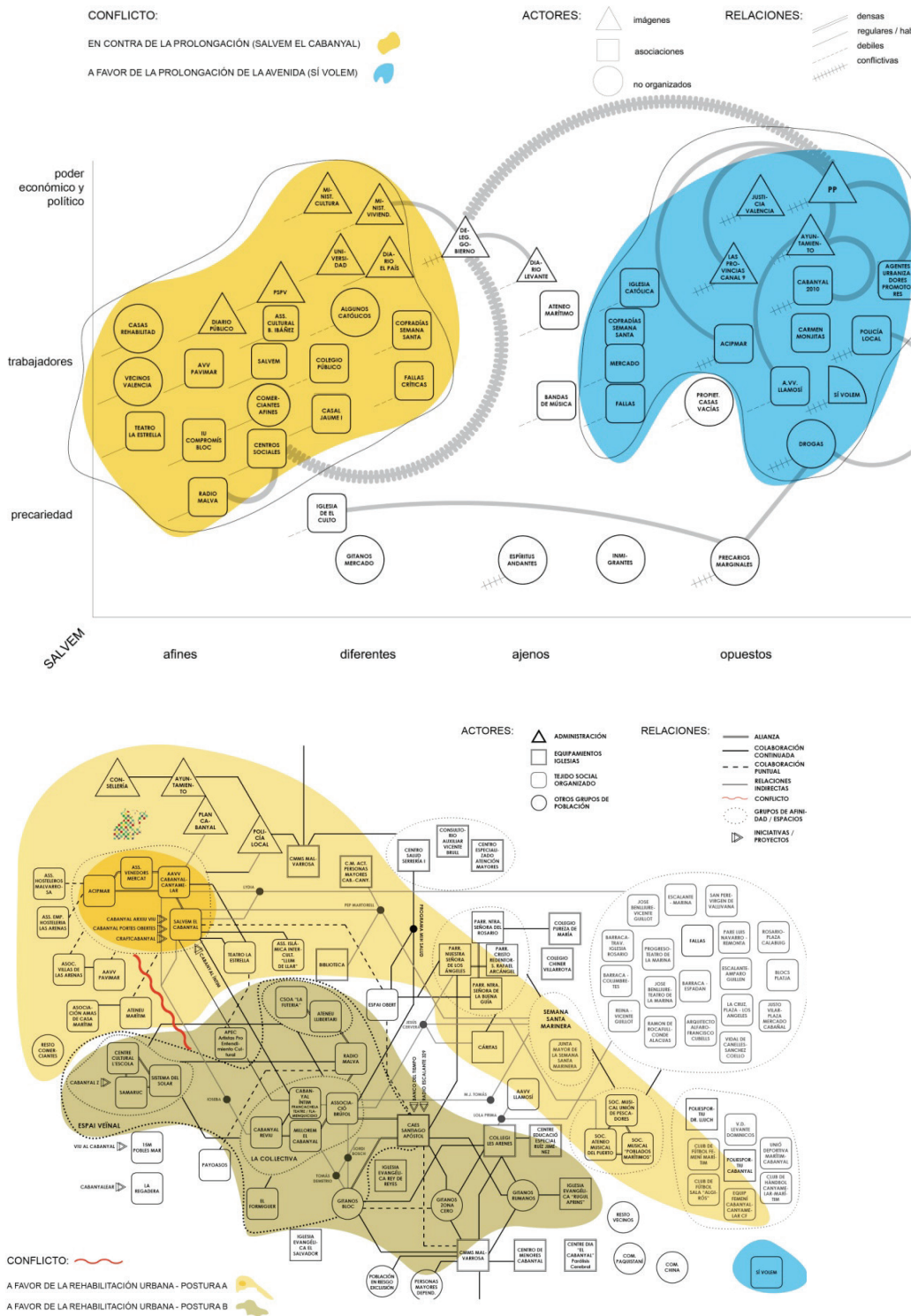




\subsection{Cap a un model de participació multidimensional ${ }^{19}$}

Amb la intenció de fer front a aquest conflicte, des de Va Cabanyal! s'intenta treballar no solament en el marc estricte de la convocatòria europea, sinó en un escenari de futur del barri on els diferents actors amb diferents interessos en la construcció de la ciutat arriben a acords puntuals, encara que siga per a redactar les línies d'acció de l'EDUSI. Davant la necessitat de crear una narració colllectiva que aprofite l'oportunitat dels fons europeus, s'intenten trencar les dinàmiques de la participació ciutadana associada a la representativitat $i$ arribar a totes les veus possibles, cosa que visibilitza certs col.lectius que fins ara havien sigut agents passius o inexistents al conflicte i que, fins i tot, acabaran posant en dubte els equilibris de poder existents en la configuració d'aquest. La lluita contra la prolongació és percebuda per part d'alguns col-lectius com a element legitimador per a prendre decisions sobre el futur del barri i davant aquest escenari emergeixen certes contradiccions, fins i tot a dintre de les pròpies associacions.

Malgrat aquest enfocament metodològic, el posicionament polaritzat de cada grup o conjunt d'acció ha tingut una conseqüència molt visible per a $\mathrm{Va}$ Cabanyal!. La regeneració del barri s'ha convertit en el camp de batalla d'una disjuntiva en la qual actualment se segueixen qüestionant aspectes que superen la dimensió local o la realitat particular del barri, com ara el debat sobre la legitimitat de l'ocupació o sobre el rebuig al model neoliberal de ciutat. Durant la redacció de l'EDUSI ja començava a evidenciar-se aquesta situació, però tot i que Va Cabanyal! va tractar de crear escenaris per a la superació d'aquest eix dominant del dilema, la falta de continuïtat del procés i diferents condicionants externs no han pogut evitar l'escalada del conflicte fins a dia d'avui.

\footnotetext{
$19 \mathrm{Amb}$ aquest terme es fa referència a la classificació de models de participació en àmbit urbà -unidimensionals i multidimensionals- establerta per Martínez (2011). Els primers fan referència a espais on, tot $\mathrm{i}$ que es distribueix en major o menor grau la capacitat de decisió al voltant del projecte de planificació, no es qüestiona la jerarquia de poder establerta, motiu pel qual es tendeix a reproduir. En canvi, els models multidimensionals ofereixen una perspectiva molt més àmplia on es concep el marc conflictualista $i$ es qüestiona l'equilibri de poder existent, "on es posen en joc les capacitats d'expressió, de debat i de decisió, obrint un espai polític per a la trobada i la negociació entre diferents col-lectius" (Martínez, 2011:28).
} 


\section{Limitacions i contradiccions del procés 4.1 L'EDUSI com a marc generador ${ }_{*+}$ i limitador}

Encara que l'EDUSI ha estat el pretext per iniciar el procés participatiu en el qual es comença a treballar de manera colllectiva sobre la regeneració del barri, també és cert que el marc d'aquesta convocatòria europea ha suposat un eix limitador. De partida, el procés és imposat per l’Administració, sense l'establiment d'un acord previ per a iniciar, just en aquest moment, un espai on siguen reconeguts tots els agents implicats. D'alguna manera, es "força" l'aprofitament que suposa l'oportunitat de generar una narració colllectiva a través de l'EDU. SI i, a més, no es consensua un marc base. Els eixos estructurants del treball venen marcats per la convocatòria europea i no tots responen a les inquietuds i necessitats dels habitants. Per exemple, els temes d'eficiència energètica no interessen $i$ açò es visibilitza en els grups de treball dels tallers.

Per altra banda, els temps administratius establerts per a presentar la proposta, acotats però a la vegada incerts, han suposat una altra limitació al procés, ja que no hi ha hagut temps material per abordar tota la complexitat del conflicte ni arribar a totes les veus existents (per exemple, al collectiu no associat d'immigrants africans o sud-americans). A més, tal com es planteja l'oportunitat per part de l'Administració, la redacció de l'EDUSI és un procés puntual que té un inici i un final. Encara que des de l'equip tècnic s'han intentat potenciar les estructures participatives existents al barri, arribar als actors i actrius no organitzats i aprofitar la inèrcia generada amb una proposta de continuïtat, realment no hi ha hagut intenció per part del consistori de consolidar un espai que perdurara en el temps i desbordara el marc establert per la convocatòria.

\subsection{L'Administració pública com a institució, altre eix limitador}

Cal destacar que el fet que la proposta de Va Cabanyal! es triara a través d'un concurs públic i fos proposada per un equip extern a l'Administració pressuposa una flexibilitat que no existeix en altres casos de contractació directa. L'equip de govern, o en aquest cas la Regidoria de Participació Ciutadana, no imposa altres limitacions que les establertes a les bases de la convocatòria europea promoguda per a aspirar a les ajudes del Fons Europeu de Desenvolupament Regional. 
No obstant això, l'estructura estratificada i compartimentada que presenta l’Ajuntament no facilita la comunicació i coordinació entre les diferents regidories, més si tenim en compte que no existeix un departament de coordinació de projectes. A més, el govern municipal està integrat per un tripartit format per tres formacions polítiques diferents $i$, a la vegada, una d'elles és coalició de tres partits polítics més. En concret, quatre de les regidories que tenen competències fonamentals en el conflicte obert del Cabanyal (Habitatge, Urbanisme, Protecció Ciutadana i Participació) tenen al capdavant regidors de diferents formacions; per tant, aglutinen sensibilitats diverses a l'hora d'intervindre el barri que tenen com a conseqüència l'aflorament de certes contradiccions visibles durant el procés -dut a terme en un context d'eleccions generals estatals-

Com hem dit anteriorment, no cal oblidar que aquestes diferents percepcions sobre la rehabilitació del barri també existien en eixe moment en el teixit veïnal, i cada vegada més polaritzades. Així, saprofita la influència del discurs d'alguns col-lectius en els mitjans de comunicació i xarxes socials per pressionar l'Ajuntament, que de certa forma cedeix o respon amb mesures puntuals que poden tenir repercussions visibles a curt termini. No com el procés participatiu de l'EDUSI, que, al marge de l'espai generat, no ha tingut encara conseqüències físiques per al desenvolupament urbà proposat. Per a una part del veïnat, aquest tipus de mesures, preses al marge del procés participatiu, donen resposta a una situació de màxima urgència que requereix ser abordada per a complir, com a entitat pública que és, amb el deure de respondre sense demora a les necessitats de la ciutadania. Per a una altra, ha servit per visibilitzar les contradiccions de l'actual Ajuntament $i$ ha posat en dubte les seues intencions d'engegar aquest procés participatiu.

\subsection{Altres limitacions}

Encara que era d'esperar — tenint en compte la situació del barri i els forts interessos econòmics en joc al voltant de la planificació urbana-, els agents immobiliaris no s'han fet ressò de la seua presència durant el procés de redacció de l'EDUSI, tot i que els negocis immobiliaris i la compravenda d'habitatges van augmentant considerablement en el barri. Tanmateix, no va existir cap tipus de pressió directa per part d'empreses que podrien veure el barri i la seua transformació com l'oportunitat per a enriquir-se. Probablement, no perquè no 
existien o perquè no era aquesta la seua intenció, sinó perquè no va haver-hi temps suficient durant la redacció de l'estratègia com perquè pogueren trobar el seu espai d'influència.

Per altra banda, els mitjans de comunicació sí que van exercir certa pressió durant el procés, sobretot la premsa escrita. En un període que va coincidir amb la campanya electoral a les eleccions nacionals, no es va desaprofitar l'oportunitat de seguir usant el Cabanyal per a afermar les estratègies de màrqueting polític. I en cert sentit, en açò també va influir la mateixa actitud de l'equip de govern, que, lluny d'establir una comunicació directa amb el barri a través de l'espai de participació que ell mateix havia generat, anà llançant notícies sobre possibles propostes futures per al front marítim, sense massa coordinació.

També s'han evidenciat certes limitacions inherents a la participació social i als models de vessant dialèctic que han intentat ser abordats per part de l'equip tècnic. Des de colllectius o associacions amb cert poder a l'hora d'establir el discurs dominant teixit al voltant del conflicte del barri, s'ha evidenciat la tendència de posar veu a aquells que tradicionalment no la tenien o d'intentar donar solucions als "problemes" d'aquells que no es manifesten amb veu pròpia al voltant del conflicte. No obstant, davant aquesta situació, i tot i que alguns sectors de població no van ser partícips de dinàmiques collectives durant la redacció col-laborativa de l'estratègia, sí que es van realitzar entrevistes grupals a través de les quals es van poder evidenciar certes contradiccions en els discursos dominants. ${ }^{20}$

\subsection{Riscos de la voràgine participativa}

Totes aquestes limitacions van evidenciar certes contradiccions respecte a la incidència real del procés en el desenvolupament urbà del barri i, sobretot, davant la concepció del consistori sobre la implicació de la població en la construcció de la ciutat.

20 Per exemple, al llarg del procés es proposa constantment la creació de cooperatives de ferralla com a mètode de legalització de la recollida de residus -tasca a la qual es dedica bona part de la població en risc d'exclusió que viu al Cabanyal. En canvi, quan s'entrevista els mateixos veïns concernits, manifesten el desig d'abandonar la recol-lecta de ferralla -tot i que existís una millora de les condicions- $\mathrm{i}$ aconseguir un "treball digne" que els permeta obtenir un sou amb el qual accedir a un habitatge i mantenir les famílies. Per aprofundir en el discurs, es pot escoltar l'entrevista "Gitanos romanesos de l'església evangèlica Rugul Aprins". [En línia: <https://www.youtube.com/watch?v=67vJTxznfYY, consultat el 08/11/2016>]. 
La participació ciutadana s'ha convertit en un dels termes més recurrents en el discurs polític actual, però existeixen tantes visions i matisos com persones en parlen. Des de l'administració local, en el cas de València, hi ha una aposta decidida per promoure processos participatius en el disseny de la ciutat. Ara bé, certs fets com la falta de resultats visibles a curt termini o la falta de coordinació entre regidories genera una sensació de desconfiança en la població que, en última instància, pot acabar afermant el risc de banalització dels processos d'aquest tipus.

D'altra banda, per a certs collectius del barri, el procés i les contradiccions emergents han demostrat la falta de compromís del consistori actual per abordar els problemes generats pel model de ciutat neoliberal, com ara la pobresa urbana, la dificultat per garantir el dret a l'habitatge o els processos de desplaçament i expulsió de les classes amb menys recursos econòmics. El fet d'engegar processos participatius puntuals que no arriben a generar estructures consolidades i reals de participació pot fer que es deixen de qüestionar públicament alguns dels efectes nefasts de les polítiques urbanes neoliberals i de la falta de justícia social $i$, tanmateix, que no saborden les causes reals per fer front al problema (Marrades y Segovia, 2015:20).

\section{Com a reflexió final: reptes a abordar}

Amb plantejaments com els de Va Cabanyal! es pretén superar models unidimensionals de participació a l’àmbit urbà de la planificació mitjançant el qüestionament de les diferents jerarquies de poder, l'abordatge dels conflictes existents i entenent la participació com a eina transformadora que no solament implica la construcció col-lectiva, sinó la justícia social. També es tracta de fonamentar el procés promogut des de l'Administració a partir dels espais de participació social ja existents. Ara bé, després d’aprofundir en el procés, són evidents les fortes limitacions existents que dificulten l'aprofitament de les oportunitats reals d'aquest enfocament, sobretot pel que respecta als obstacles que imposa el marc administratiu i institucional (Ariza, 2016:64). Així doncs, cal reflexionar profundament sobre aquestes si volem aconseguir que la implicació de la ciutadania en la planificació i transformació de les ciutats es convertisca en una eina realment transformadora. 
Durant l'any 2016 s'ha produït una paralització completa del procés impulsat per Va Cabanyal!. El prolongat termini administratiu d'avaluació de l'estratègia presentada ha suposat la interrupció del procés de redacció — dut a terme durant els quatre últims mesos del 2015 — i la seua implementació —que suposadament començarà al llarg de 2017. Aquest impàs ha trencat la inèrcia i el potencial que tenien algunes de les estructures de participació creades (grup motor, oficina de barri, web...) i ha deixat oberts multitud de conflictes sorgits que, necessàriament, haurien d'haver-se treballat dins d'un procés de negociació i mediació. Tenint en compte les limitacions i contradiccions entre les quals s'ha desenvolupat el procés, podríem considerar que la redacció de l'estratègia ha estat només un assaig previ de la seua implementació. Són molts els reptes a afrontar i la tasca no és gens fàcil, però la pràctica participativa ha de ser un procés constant d'assaig-error, on combinar la praxi amb la reflexió pot ajudar a generar hipòtesis de millora. Per tant, amb la intenció de fer front a les limitacions sorgides en el context de la implementació i amb un horitzó temporal més extens (2017-2021), es considera oportú incidir en el desenvolupament de les característiques pròpies dels models multidimensionals, els quals aporten una concepció molt més àmplia i complexa del fenomen de la participació (Martínez, 2011:36). Com a reflexió final, i molt breument, sanuncien algunes consideracions a tindre en compte com a futurs reptes:

1) Superar el marc de l'EDUSI i l'escala de barri.

El procés d'implementació de l'EDUSI ha d'anar més enllà de la presa de decisió sobre l'execució, seguiment i avaluació de certes intervencions emmarcades en l'estratègia, $i$ ha de començar a treballar en estructures de comunicació, aprenentatge, negociació i superació que sobrepassen l'horitzó temporal de cinc anys. Superar necessàriament l'escala de barri incidint en la transformació del model de ciutat que fins ara s' ha desenvolupat.

2) Potenciar el paper de l'Administració com a garant d'un "entorn favorable" des del seu paper d'institució (lluita contra la pobresa urbana, dret a l'habitatge...).

Si realment es vol incidir en l'augment del poder social, polític i psicològic, incrementant la influència dels col-lectius exclosos, haurem de començar a desenvolupar polítiques que cobrisquen les "necessitats bàsiques" dels col-lectius més desafavorits. En primer lloc, una política pública d'habitatge que aprofite la gran quantitat de patrimoni municipal de sòl i vivenda al barri i continga 
l'increment de preu derivat de les noves expectatives urbanes, evitant -0 , tant que siga, frenant - la seua elitizació o gentrificació. Així com moltes altres polítiques municipals que influiran en el desenvolupament del barri com per exemple les de mobilitat, turisme, comerç, ocupació i accés als serveis bàsics. És per això imprescindible que es treballe per afavorir la coordinació de totes les regidories competents.

3) Generar estructures de participació vinculants i transformadores.

A escala de barri, és necessari el suport a les iniciatives independents que sorgeixen de les mateixes organitzacions socials, mitjançant el reconeixement de la seua legitimitat i capacitat transformadora. La construcció d'espais de trobada i participació informals que reforcen el diàleg entre agents d'interessos dispars, i que incideixen en la transformació de les relacions establides entre els diferents colllectius, també poden afermar aquestes estructures. S'ha d'abordar la participació com a pràctica comunicativa i transformadora de les relacions de poder existents, posant l'accent en l'anàlisi prèvia de les desigualtats de partida dels diferents agents involucrats. Així, és important fomentar el paper dels actors pont, aquells capaços establir vincles entre conjunts d'acció (Red CIMAS, 2010:27) o conjunts d'interès homogenis, sense oblidar que l'Administració és un agent més en el procés de planificació.

En última instància, però no per això menys rellevant, cal ser conscient que aquest canvi de dinàmiques ha de permeabilitzar-se a l'estructura administrativa. Els personal tècnic i polític ha de començar a assimilar el seu paper de facilitador del debat, així com de construcció de qüestions per al debat, materialitzant una cessió de poder real en la presa de decisions. És necessari treballar la complexitat que suposa la ciutat i la seua planificació des de la coordinació de les estructures de govern. 


\section{Bibliografia}

Ariza, A. (2016): "Participación en el ámbito de la planificación urbana. El Caso de Va Cabanyal!" Treball Final del Màster. Tarragona: Universitat Rovira i Virgili.

Azorín, F; Caparrós, P; Català, Ll.; González, I.; Raga, E. (2016): "Más allá del simulacro: redacción colaborativa de la EDUSI del barrio del Cabanyal-Canyamelar-Cap de França (Valencia)". Sociologiados. Revista de Investigación Social, vol. 1, núm. 1, 2016; pàg. 119-140.

Benlloch, Ll. (2013): “Tras la senda del desplazamiento. Valencia (19952007)". Concreta, núm. 1. [En línia: <http://editorialconcreta.org/Tras-lasenda-del-desplazamiento, consultat el 07/06/2016> ]

Cucó, J. (Ed.) (2013): Metamorfosis Urbanas. Ciudades españolas en la dinámica global. Barcelona: Icaria.

Cucó, J. (2014): “Periferias junto al mar. A propósito de los poblados marítimos de Valencia”. Actas del XIII Congreso de Antropología. Periferias, Fronteras y Diálogos. Tarragona: Universitat Rovira i Virgili. Pàg 40-61.

Cuesta, R. (2011): “Procesos de asimilación y resistencia urbanas en el marco de la globalización. Aproximaciones al barrio chino de Barcelona y al barrio del Cabanyal de Valencia”. Revista Nuevas Tendencias en Antropología, núm. 2, pàg. 104-146.

Equip Va Cabanyal! (2015): "Proposta per a la formulació d'una estratègia integrada de desenvolupament urbà sostenible en València per al període 2015-2020. Àrea de actuació: Cabanyal. Ampiable a altres poblats marítims". València. [En línia: <http://vacabanyal.org/wp-content/ uploads/2015/09/PROPOSTA_estrategia_VA_CABANYAL.pdf, consultat el 18/12/2016>].

Herrero, L. F. (2010): "Vida en el barrio: Cabanyal, un conjunto histórico protegido... y amenazado”. Ingeniería y Territorio, núm. 75, pàg. 86-95. [En línia: <http://www.ciccp.es/revistaIT/portada/index.asp?id=330, consultat el 18/12/2016>].

Herrero, L. F; Soldevila, M. (2010): "La plataforma Salvem El Cabanyal: doce años de lucha ciudadanas". Revista de Patrimonio Histórico, núm. 6, pàg. 100-116. [En línia: <http://revistaseug.ugr.es/index.php/erph/article/view/3375/3387>, consultat el 18/12/2016]. 
Herrero, L. F; Varea, A. (2012): I Congreso Internacional sobre Permanencia y Transformación en Conjuntos Históricos. València, Editorial de la Universitat Politècnica de València.

Grupo Aürt - Ateneu Llibertari del Cabanyal (2015): De la Prolongació a la Gentrificació - Reflexions sobre el conflicte del Cabanyal. València: Edició pròpia.

Martínez, M. (2006): "La participación social en el urbanismo, en los límites de la realidad". Biblioteca de Ciudades para un Futuro más Sostenible, núm. 34. [En línia: <http://habitat.aq.upm.es/boletin/n34/ammar.html, consultat el 18/12/2016>].

Martínez, M. (2007): “Complejidad y participación: la senda de la invención estratégica”. Política y sociedad, vol. 44, núm 1, pàg. 31-53.

Martínez, M. (2011): “Dimensiones múltiples de la participación ciudadana en la planificación espacial”. Reis núm. 133, pàg. 21-42.

Martínez, M. (2014): "Participación, conflicto y planificación: autocrítica y herramientas teóricas". Diversos autors: Planificación participativa: Critica, métodos y experiencias. Construyendo Ciudadanía/13. Madrid: Observatorio Internacional de Ciudadanía y Medio Ambiente Sostenible (CIMAS). [En línia: <http://www.redcimas,org/wordpress/wp-content/ uploads/2015/08/LIBRO-PLANIFICACION-PARTICIPATIVA-13. pdf, consultat el 18/12/2016>].

Marrades, R.; Segovia, C., (2015): "Y del proceso al plan”. Diagonal núm. 40, pàg. 16-20.

Red CIMAS (2010): Manual de metodologías participativas. Madrid: Edició pròpia. [En línia: <http://www.redcimas.org/wordpress/wp-content/ uploads/2012/09/manual_2010.pdf, consultat el 18/12/2016>].

Rodríguez Villasante, T. (2004): "La socio-praxis: un acoplamiento de metodologías implicativas”. [En línia: <http://virtual.funlam.edu.co/repositorio/sites/default/files/repositorioarchivos/2010/03/Socio-praxisTomasR\%20Villasante.354.pdf, consultat 18/12/2016> ].

Rodríguez Villasante, T. (2014): Redes de vida desbordantes. Fundamentos para el cambio desde la vida cotidiana. Madrid, La Catarata.

Ruiz, M. A.; García, P., (2013): "Disolución del lugar y espacios del miedo en el Cabanyal”. A: Cucó, J. (Dir.), 2013. La ciudad pervertida. Una mirada sobre la Valencia global. Barcelona: Antrhopos Editorial. Pàg. 67-92. 
Santamarina, B. (2014): "El oficio de la resistencia. Salvem y Viu al Cabanyal como formas de contención del urbanismo neoliberal". Revista de Dialectología y Tradiciones Populares, vol. LXIX, núm. 2, pàg. 305-326. [En línia: <http://dx.doi.org/10.3989/rdtp.2014.02.003, consultat el $16 / 05 / 2017>$ ].

Varea, A.; Bascuñana, P.; Català, Ll.; Caparrós, P.; Azorín, F., (2016): "Construir la ciudad colectivamente. De la exclusión social al bien común". A: Medio Ambiente y Politica Social. Análisis y perspectivas Comunitat Valenciana. Observatorio de Investigación sobre Pobreza y Exclusión en la Comunitat Valenciana. Pàg. 99-112. 
